\title{
Prevalence and characteristics of chronic body pain in China: a national study
}

\author{
Beifeng Chen ${ }^{1}$, Linlin Li ${ }^{2}$, Connor Donovan ${ }^{3}$, Yongqing Gao ${ }^{4}$, Gholam Ali ${ }^{5}$, Yan Jiang ${ }^{6}$, Tan Xu ${ }^{7,8^{*}}$, \\ Guangliang Shan ${ }^{9^{*}}$ and Wenjie Sun ${ }^{4,8^{*}}$
}

\begin{abstract}
Background: Chinese citizens regularly experience some form of bodily pain, yet little is known regarding the epidemiology of pain.

Methods: We conducted a nationally representative sample cross sectional study to estimate the prevalence of pain and identify risk factors of pain among 19,665 community residents aged 18-65 years in China. The China Sub-optimal Health Survey (CSHS) data was used to estimate pain prevalence. Body pain was also estimated by self-reports from the sample population. A logistical regression model was applied to estimate the odds ratio and $95 \% \mathrm{Cls}$ of acute pain and chronic pain to explore the potential risk factors.

Results: Women had a higher prevalence of pain than men (39.92 vs. $32.17 \%$ for chronic pain). The prevalence of pain increased with age ( $29.72 \%$ for ages $18-25$ vs. $42.23 \%$ for ages $45-65)$. The most common complaints were head, neck/shoulder, and waist/back pain. Females (OR 1.57, $95 \%$ Cl 1.44-1.71) ages 25 or older (25-45: OR 1.19, $95 \%$ Cl 1.04-1.36; 45-65: OR 1.47, $95 \%$ Cl 1.26-1.73) were more likely to report having chronic pain. Subjects'living areas, and their drinking status (OR 1.32, $95 \% \mathrm{Cl} 1.13-1.53)$ or smoking status (OR 1.01, $95 \% \mathrm{Cl}$ 0.91-1.11), were also factors that were significantly associated with increased reporting of chronic pain.

Conclusion: Women had a higher prevalence of chronic pain than men, although both sexes had a high prevalence for chronic pain. There were significant differences between the two sexes and the location of chronic pain in the body, most notably in the shoulders, stomach, abdomen, and waist.
\end{abstract}

Keywords: Pain, Prevalence, China

\section{Background}

It is common for the general population to suffer from physical pain in the body. Nearly one in three adults worldwide experiences some sort of physical pain (Tsang et al. 2008). Very few studies have explored body pain in the general population, although there are some studies found in clinical settings. Previous epidemiological studies of the general population have shown that body pain varies from 8.7 to $42.0 \%$ among adults in different

\footnotetext{
*Correspondence: xutan@suda.edu.cn; guangliang_shan@hotmail.com; wsun3@tulane.edu

${ }^{8}$ Tulane University, School of Public Health and Tropical Medicine, 1440 Canal Street, New Orleans, LA 70112, USA

${ }^{9}$ Department of Epidemiology and Statistics, Institute of Basic Medical Sciences, Chinese Academy of Medical Sciences; School of Basic Medicine, Peking Union Medical College, Beijing 100005, China Full list of author information is available at the end of the article
}

countries (Yeo and Tay 2009; Cabral et al. 2014; Duenas et al. 2015). The wide variation in prevalence of pain could be partially explained by methodological, racial/ ethnical, or cultural differences (Johannes et al. 2010). Evidence strongly suggests that complaints of pain are more common among the obese (Dario et al. 2015; Okifuji and Hare 2015), women (Boerner et al. 2015; Tighe et al. 2014; Oliva et al. 2015), middle aged individuals (LeResche et al. 2015; Houde et al. 2015), and individuals of lower socioeconomic status (SES) (Latza et al. 2000). However, most of the studies referenced above were from Western countries. There is limited information available on body pain in China. A community-based study conducted in Chongqing, China reported that the prevalence of body pain among the local adult population was $42.2 \%$ (Jackson et al. 2014). A Hong Kong population-based 
study showed that $34.9 \%$ of the surveyed population reported pain lasting more than 3 months (chronic pain) and an average of 1.5 pain sites in the body; $35.2 \%$ experienced multiple pain sites, with the majority of respondents rating the legs and back as the sites with the most prevalent pain (Wong and Fielding 2011). While the results of the aforementioned studies are significant, it is difficult to draw conclusions from the results due to the lack of representativeness in the studies' sample populations. Hence, a national population-based study was needed to examine the prevalence of chronic body pain among the Chinese population, potentially providing significant indicators that might aid in preventing this chronic health condition in Chinese citizens.

The objectives of this study were to investigate: (1) the prevalence of body pain in the general Chinese adult population, and (2) the socio-demographic, clinical, and social risk factors of body pain.

\section{Methods}

\section{Study design and data collection}

The methodology of the study was reported elsewhere (Sun et al. 2015). In brief, the Chinese Sub-optimal Health Study (CSHS) is a cross-sectional study, with China's population of 1.4 billion people being represented by participants from six Chinese provinces, selected through a multi-stage, random cluster sampling design. All 31 provinces or municipalities were divided into six administrative regions (Northeast, North, East, Central South, Southwest, and Northwest) based on their geographic locations. Six provinces (Jilin, Beijing, Jiangsu, Hubei, Sichuan, and Gansu) were randomly selected from within each administrative region to represent the entire region. Within each selected province, residents, including local college students, government staff, business and farm workers, and other non-affiliated local residents, were clustered and randomly selected for the study sample. Selected participants were asked to complete a self-administered questionnaire. The data on demographic and personal characteristics were collected, including: gender, age, marital status, education, smoking status, drinking status, and health information (medical history, illnesses, and diseases that occurred during the last 12 months). Information on occupation was based on Chinese labor law.

19,665 participants were selected for the study, of which 18,631 responded and completed the questionnaire (response rate: $94.7 \%$ ). We excluded individuals who (1) were younger than 18 or older than 65 years of age; and (2) had mental illnesses that might prevent them from providing accurate information in terms of body pain. After exclusion, 16,174 eligible participants were included in the final analysis.

\section{Ethics statement}

This study was approved by the Institutional Review Board at Peking Union Medical College and followed the tenets of the Declaration of Helsinki. Written informed consent was obtained from all participants.

\section{Outcome: chronic body pain}

In the present study, chronic body pain was defined as ongoing and having occurred for more than 3 months (Jackson et al. 2014), which was consistent with the definition used in the literatures. Chronic pain was assessed by two questions:

1. Have you had chronic body pain? If yes, please specify the site of pain.

2. Did the body pain affect your life?

Respondents were asked to rate body pain using a Likert scale $(1=$ Not at all, $2=$ Very few, $3=$ Sometimes, $4=$ Very often, and $5=$ Almost all the time).

\section{Statistical analyses}

All data analyses were performed using Windows Statistical Software Package Version 10.0 (SAS Institute, Cary, NC, USA). Participant occupation was analyzed as a categorical variable. Body pain was re-categorized into two groups (Yes/No), which were investigated as binary outcome variables. Health status was assessed based on self-reported chronic conditions including: hypertension, diabetes, coronary heart disease, hyperlipidemia, hepatitis, and other diseases. Participants with any of the chronic diseases mentioned above were classified as being in an "unhealthy" condition.

Chi square tests were used to compare the demographic characteristics between participants who have acute body pain and those who have chronic body pain. Tukey's tests were used to compare the difference between sub-groups. Logistical regression models were applied to examine the potential risk factors (sex, age, occupation/education, area, marriage, smoking status, drinking status, and health status) of chronic body pain. All risk factors were categorized as in Table 1 (A significance level of 0.05 is required to allow the variable to enter into the model). All the tests were two sided and the significance level was set at 0.05 .

\section{Results}

The study included a total of 16,174 Chinese adults, $50.3 \%$ male and $49.7 \%$ female, ages $18-65$ with a mean age of $33.2(\mathrm{SD}=10.5)$. Table 1 shows the prevalence of chronic body pain by each characteristic. Women had a higher prevalence of chronic pain than men (39.9 vs. $32.2 \%)$. The prevalence of pain increased with older 
Table 1 Prevalence of chronic pain and percentage of affected individuals

\begin{tabular}{|c|c|c|}
\hline & Prevalence & Affected \\
\hline \multicolumn{3}{|l|}{ Sex } \\
\hline Men & 32.17 & 29.21 \\
\hline Women & 39.92 & 34.72 \\
\hline \multicolumn{3}{|l|}{ Age (years) } \\
\hline $18-25$ & 29.72 & 33.15 \\
\hline $25-\leq 45$ & 36.97 & 30.85 \\
\hline $45-\leq 65$ & 43.23 & 33.63 \\
\hline \multicolumn{3}{|l|}{ Occupation } \\
\hline Civil & 37.88 & 30.42 \\
\hline Profession & 41.35 & 33.69 \\
\hline Worker & 37.75 & 31.48 \\
\hline Famer & 33.92 & 32.32 \\
\hline Business man/service & 31.15 & 27.65 \\
\hline Students & 30.84 & 35.79 \\
\hline Others & 33.70 & 30.37 \\
\hline \multicolumn{3}{|l|}{ Education } \\
\hline Liberate/primary school & 35.80 & 31.27 \\
\hline High school & 34.69 & 30.61 \\
\hline College & 36.74 & 32.87 \\
\hline \multicolumn{3}{|l|}{ Area } \\
\hline Jilin & 56.15 & 37.21 \\
\hline Gansu & 33.15 & 32.90 \\
\hline Sichuan & 32.36 & 33.32 \\
\hline Jiangsu & 21.32 & 22.86 \\
\hline Hubei & 39.41 & 34.98 \\
\hline Beijing & 40.37 & 31.42 \\
\hline \multicolumn{3}{|l|}{ Marriage } \\
\hline Single & 30.84 & 33.23 \\
\hline Married & 38.38 & 31.09 \\
\hline Devoice/separate/Widow & 43.73 & 37.10 \\
\hline \multicolumn{3}{|l|}{ Smoking } \\
\hline No & 36.52 & 32.79 \\
\hline Yes & 34.44 & 29.27 \\
\hline \multicolumn{3}{|l|}{ Drinking } \\
\hline No & 35.99 & 32.79 \\
\hline Yes & 36.11 & 30.09 \\
\hline \multicolumn{3}{|l|}{ Healthy } \\
\hline Yes & 32.24 & 29.55 \\
\hline No & 48.78 & 40.05 \\
\hline
\end{tabular}

age (29.72\% for ages $18-25$ vs. $42.23 \%$ for ages $45-65)$. Professional workers (41.4\%) had the highest prevalence of chronic pain compared to other occupations, while students had the lowest prevalence (30.8\%). Smokers, drinkers, and people in "unhealthy" conditions also had a higher prevalence of chronic pain compared to their counterparts.
Results of univariate analyses showed that only one of the seven socio-demographic variables (religion) did not meet the pre-selection criteria $(\mathrm{P}<0.05)$. Hence, all the other six socio-demographic variables were entered in the multivariate model (Table 2). Females (vs. males) (OR $1.57,95 \%$ CI 1.44-1.71), and individuals aged 25 or older (vs. ages 18-24) (25-45: OR 1.19, 95 \% CI 1.04-1.36;

Table 2 Factors associated with pain

\begin{tabular}{|c|c|}
\hline & $\begin{array}{l}\text { Chronic pain } \\
\text { Adjusted OR }\end{array}$ \\
\hline \multicolumn{2}{|l|}{ Sex } \\
\hline Men & Ref \\
\hline Women & $1.57(1.44-1.71)^{*}$ \\
\hline \multicolumn{2}{|l|}{ Age (years) } \\
\hline $18-25$ & Ref \\
\hline $25-\leq 45$ & $1.19(1.04-1.36)^{*}$ \\
\hline $45-\leq 65$ & $1.47(1.26-1.73)^{*}$ \\
\hline \multicolumn{2}{|l|}{ Occupation } \\
\hline Civil & $0.87(0.77-0.98)^{*}$ \\
\hline Profession & $1.13(1.00-1.28)^{*}$ \\
\hline Worker & Ref \\
\hline Famer & $0.98(0.85-1.14)$ \\
\hline Business man/service & $0.95(0.82-1.09)$ \\
\hline Students & $1.03(0.88-1.20)$ \\
\hline Others & $0.90(0.78-1.04)$ \\
\hline Education & Ref \\
\hline Liberate/primary school & $1.01(0.91-1.12)$ \\
\hline High school & $1.08(0.96-1.20)$ \\
\hline \multicolumn{2}{|l|}{ College } \\
\hline \multicolumn{2}{|l|}{ Area } \\
\hline Jilin & Ref \\
\hline Gansu & $0.44(0.39-0.49)^{*}$ \\
\hline Sichuan & $0.36(0.32-0.41)^{*}$ \\
\hline Jiangsu & $0.25(0.22-0.28)^{*}$ \\
\hline Hubei & $0.57(0.51-0.64)^{*}$ \\
\hline Beijing & $0.56(0.49-0.63)^{*}$ \\
\hline \multicolumn{2}{|l|}{ Marriage } \\
\hline Single & $0.94(0.83-1.06)$ \\
\hline Married & Ref \\
\hline Devoice/separate/widow & $1.11(0.90-1.37)$ \\
\hline \multicolumn{2}{|l|}{ Smoking } \\
\hline No & Ref \\
\hline Yes & $1.01(0.91-1.11)$ \\
\hline \multicolumn{2}{|l|}{ Drinking } \\
\hline No & Ref \\
\hline Yes & $1.10(1.00-1.20)^{*}$ \\
\hline \multicolumn{2}{|l|}{ Healthy } \\
\hline Yes & Ref \\
\hline No & $1.94(1.78-2.11)^{*}$ \\
\hline
\end{tabular}


45-65: OR 1.47, 95 \% CI 1.26-1.73) were more likely to report having chronic pain.

Respondents with chronic diseases were more likely to report acute pain compared to those without chronic diseases (OR 1.94, 95 \% CI 1.78-2.11). Drinking alcohol (OR 1.32, $95 \%$ CI 1.13-1.53) and smoking cigarettes (OR $1.01,95 \%$ CI 0.91-1.11) were factors significantly associated with increased odds of chronic body pain.

The sites of the body pain are shown in Table 3. For men, the main sites for body pain were in the head $(29.7 \%)$, neck and shoulders (24.5\%), followed by waist and back (22.5\%), and then the stomach (17.2\%). For women, the main sites for body pain were in the head (36.7 \%), neck and shoulders (32.4\%), followed by waist and back (26.4\%), and then the stomach (20.7\%).

\section{Discussion}

Our results suggest that 35.9 \% of the Chinese population suffers from chronic body pain and the pain is mostly prevalent around the head, neck/shoulders, and waist/back. Individuals who are female or older, who have a low SES, or who have chronic diseases are independently associated with a higher prevalence of body pain; the overall prevalence of chronic body pain in our study is very close to previous findings on chronic body pain found in Chinese adults in certain areas, such as in Hong Kong (from 34.9 to 45.9 \%) (Wong and Fielding 2011; Chung and Wong 2007), Taiwan (42.0\%) (Yu et al. 2006), and Chongqing (25.8 \%) (Jackson et al. 2014). Of note, a Singapore study reported that the prevalence of pain among.

Chinese in Singapore was $8.7 \%$ (Yeo and Tay 2009), which was much lower than the prevalence in other areas. However, this study excluded people who were living in nursing homes and who were cognitively impaired, which could potentially under-estimate the prevalence of chronic body pain. Breivik et al. (2006) conducted

Table 3 The percentage of pain in various body locations in the two sexes

\begin{tabular}{lrccc}
\hline & Male & Female & Total & P value \\
\hline Pain site & & & & \\
Head & 29.65 & 36.71 & 33.13 & $<0.0001$ \\
Shoulder & 24.49 & 32.41 & 28.39 & $<0.0001$ \\
Stomach & 17.23 & 20.72 & 18.95 & $<0.0001$ \\
Abdominal & 9.06 & 16.86 & 12.90 & $<0.0001$ \\
Waist & 22.52 & 26.38 & 24.42 & $<0.0001$ \\
Joint & 14.66 & 14.58 & 14.62 & 0.12 \\
Limbs & 12.69 & 12.23 & 12.46 & 0.08 \\
Chest & 6.88 & 6.19 & 6.54 & 0.02 \\
Others & 0.39 & 0.43 & 0.41 & 0.64 \\
\hline
\end{tabular}

* P for the difference between sexes a large-scale computer-assisted telephone survey to explore the prevalence, severity, treatment and impact of chronic pain in 15 European countries and Israel. They found that $19 \%$ of 46,394 respondents had suffered pain for 6 months. Compared to the countries in Breivik et al's study, the prevalence of chronic pain in China is high. However, Breivik et al. reported that $61 \%$ of respondents were less able or unable to work outside the home, which is higher than the result found in this study. The different results from these studies could be attributed to differences in sample populations, sampling methods, measurements, and culture factors.

Our results also indicated that the main sites for body pain were in the head, neck/shoulders, and waist/back. Jackson et al. (2014) found that the most common complaints among Chinese people in Chongqing came from back pains (17.6\%), headaches (14.2\%), joint pains (10.5\%), and abdominal pains (10.4\%). Additionally, in our sample, $8.4 \%$ of people reported that acute pain affected their lives, and $31.9 \%$ of people reported that chronic pain affected their lives. The combined prevalence of body pain is consistent with previously reported findings. For example, a Spanish study found that $47.2 \%$ of Spanish people indicated that body pain was affecting their family life (Duenas et al. 2015). However, this data was not comparable to our results due to inconsistent sampling methodology and different study population.

Our study also described potential risk factors that might lead to a greater prevalence of pain, e.g. being female, aging, and being deemed "unhealthy," which were also reported by previous studies (Yeo and Tay 2009; Cabral et al. 2014). In our sample, compared to workers, the prevalence of body pain among civil servants was significantly lower. A few previous studies reported similar findings indicating that complaints of body pain could differ by occupation (Yue et al. 2012; Liu et al. 2012). Our results also suggested that low SES was associated with higher rates of chronic pain, which was consistent with previous studies (Bonathan et al. 2013). Of note, a person's occupation (one important component of socioeconomic status) is associated with lower back pain. For instance, Jin et al. (2004) conducted a cross-sectional study in China and found that garment workers had a higher annual prevalence of lower back pain $(74 \%)$ than teachers (40\%) (PR 1.9, $95 \%$ CI 1.4-2.4); this could be explained by the garment workers' long duration of sedentary positions. Miljković et al. (2014) investigated the association of experimentally induced pain threshold and tolerance with socioeconomic status, and their results suggested that poor people have a higher prevalence of pain. A significant association was found between the experimentally induced pain threshold and tolerance and marital socioeconomic status. This finding indicated 
that poor people indeed do hurt more. Our study could have major public health implications (Riskowski 2014). Due to the aging of the Chinese population, body pain will increase significantly in the coming future. Chen et al. (2015) conducted a study on physical therapy and lower back pain among patients in Guangdong, China. They found that the willingness-to-pay for acupuncture and low-frequency infrared treatment was about $\$ 618.6$ and \$592.4 USD per course, respectively. It demonstrated patients' demand for pain management. Lacking effective pain management, the recurrence of the body pain is high (Chu et al. 2015). Further studies on pain management are warranted.

The strengths of this study include the large sample size and the adjustments for other important confounders (age, sex, occupations, etc.). Theoretically, chronic body pain should be measured by intensity. However, in the practice, there are no standardized objective criteria to measure the intensity of chronic pain due to the inconsistency of individuals' sensitivity to pain; this was addressed in this study. In addition, this study also measured the frequency of chronic pain in individuals, an aspect of body pain that needed further evaluation.

This study does have several limitations. Pain data was self-reported which can be imprecise and subject to reporting bias. Furthermore, there are no validated tools for assessing self-reported pain. Future studies with pain scales are warranted. In addition, data on depression (Chen et al. 2012) and pain killers, which could be potential confounders, was not available. Lastly, adverse life events and psychological distress could have had mediating effects on the association between individuals' socioeconomic status and their reported body pain (Macfarlane et al. 2009).

\section{Conclusion}

The prevalence of body pain among Chinese adults was high. Being female, aging, having a low SES, and possessing chronic diseases were independent factors associated with higher prevalence of pain. Women had a higher prevalence of chronic pain than men, although both sexes had a high prevalence for chronic pain. There were significant differences between the two sexes and the location of chronic pain in the body, most notably in the shoulders, stomach, abdomen, and waist.

\section{Authors' contributions \\ Conceived and designed the experiments: TX, WS, GS. Performed the experi- ments: TX, GS. Analyzed the data: WS. Contributed reagents/materials/analysis tools: TX. Wrote the paper: BC, WS, YJ, YG, LL. Revised the paper: CD, AG. All authors read and approved the final manuscript}

\section{Author details}

${ }^{1}$ School of Public Health, Wannan Medical College, Wuhu 241002, China.

2 University of California Davis Health System, Sacramento, CA 95817, USA.

${ }^{3}$ College of Business, University of Arkansas at Little Rock, Little Rock, AR, USA.
${ }^{4}$ School of Food Science, Guangdong Pharmaceutical University, Zhongshan 528458, China. ${ }^{5}$ School of Medicine, Tulane University, New Orleans, LA 70112, USA. ${ }^{6}$ Infocast Company, Kowloon, Hong Kong. ${ }^{7}$ Department of Epidemiology, School of Public Health and Jiangsu Key Laboratory of Preventive and Translational Medicine for Geriatric Diseases, Medical College of Soochow University, Suzhou, Jiangsu Province 215123, China. ${ }^{8}$ Tulane University, School of Public Health and Tropical Medicine, 1440 Canal Street, New Orleans, LA 70112, USA. ${ }^{9}$ Department of Epidemiology and Statistics, Institute of Basic Medical Sciences, Chinese Academy of Medical Sciences; School of Basic Medicine, Peking Union Medical College, Beijing 100005, China.

\section{Acknowledgements}

We wish to thank all the participants for their co-operation in the data collection.

\section{Competing interests}

The authors declare that they have no competing interests.

Received: 18 February 2016 Accepted: 15 June 2016

Published online: 30 June 2016

\section{References}

Boerner KE, Schinkel M, Chambers CT (2015) It is not as simple as boys versus girls: the role of sex differences in pain across the lifespan. Pain Manag $5(1): 1-4$

Bonathan C, Hearn L, Williams AC (2013) Socioeconomic status and the course and consequences of chronic pain. Pain Manag 3(3):159-162

Breivik H, Collett B, Ventafridda V, Cohen R, Gallacher D (2006) Survey of chronic pain in Europe: prevalence, impact on daily life, and treatment. Eur J Pain (London, England) 10(4):287-333

Cabral DM, Bracher ES, Depintor JD, Eluf-Neto J (2014) Chronic pain prevalence and associated factors in a segment of the population of Sao Paulo City. J Pain 15(11):1081-1091

Chen X, Cheng HG, Huang Y, Liu Z, Luo X (2012) Depression symptoms and chronic pain in the community population in Beijing, China. Psychiatry Res 200(2-3):313-317

Chen LC, Cheng LJ, Zhang Y, He X, Knaggs RD (2015) Acupuncture or low frequency infrared treatment for low back pain in Chinese patients: a discrete choice experiment. PLOS ONE 10(5):e0126912

Chu MC, Law RK, Cheung LC et al (2015) Pain management programme for Chinese patients: a 10-year outcome review. Hong Kong Med J 21(4):304-309

Chung JW, Wong TK (2007) Prevalence of pain in a community population. Pain Med (Malden, Mass.) 8(3):235-242

Dario AB, Ferreira ML, Refshauge K et al (2015) Are obesity and body fat distribution associated with low back pain in women? A populationbased study of 1128 Spanish twins. Eur Spine J, the European Spinal Deformity Society, and the European Section of the Cervical Spine Research Society

Duenas M, Salazar A, Ojeda B et al (2015) A nationwide study of chronic pain prevalence in the general spanish population: identifying clinical subgroups through cluster analysis. Pain Med (Malden, Mass.) 16(4):811-822

Houde F, Cabana F, Leonard G (2016) Does age affect the relationship between pain and disability? A descriptive study in individuals suffering from chronic low back pain. J Geriatr Phys Ther 39(3):140-145. doi:10.1519/ JPT.0000000000000055

Jackson T, Chen H, lezzi T, Yee M, Chen F (2014) Prevalence and correlates of chronic pain in a random population study of adults in Chongqing, China. Clin J Pain 30(4):346-352

Jin K, Sorock GS, Courtney TK (2004) Prevalence of low back pain in three occupational groups in Shanghai, People's Republic of China. J Saf Res 35(1):23-28

Johannes CB, Le TK, Zhou X, Johnston JA, Dworkin RH (2010) The prevalence of chronic pain in United States adults: results of an Internet-based survey. J Pain 11(11):1230-1239

Latza U, Kohlmann T, Deck R, Raspe H (2000) Influence of occupational factors on the relation between socioeconomic status and self-reported back 
pain in a population-based sample of German adults with back pain. Spine. 25(11):1390-1397

LeResche L, Saunders K, Dublin S et al (2015) Sex and age differences in global pain status among patients using opioids long term for Chronic noncancer pain. J Women's Health 24(8):629-635

Liu X, Wang L, Stallones L et al (2012) Back pain among farmers in a northern area of China. Spine 37(6):508-514

Macfarlane GJ, Norrie G, Atherton K, Power C, Jones GT (2009) The influence of socioeconomic status on the reporting of regional and widespread musculoskeletal pain: results from the 1958 British Birth Cohort Study. Ann Rheum Dis 68(10):1591-1595

Miljkovic A, Stipcic A, Bras M et al (2014) Is experimentally induced pain associated with socioeconomic status? Do poor people hurt more? Med Sci Monit 20:1232-1238

Okifuji A, Hare BD (2015) The association between chronic pain and obesity. J Pain Res 8:399-408

Oliva EM, Midboe AM, Lewis ET et al (2015) Sex differences in chronic pain management practices for patients receiving opioids from the Veterans Health Administration. Pain Med (Malden, Mass.) 16(1):112-118

Riskowski JL (2014) Associations of socioeconomic position and pain prevalence in the United States: findings from the National Health and Nutrition Examination Survey. Pain Med (Malden, Mass.) 15(9):1508-1521
Sun W, Yu Y, Yuan J et al (2015) Sleep duration and quality among different occupations-China national study. PLoS ONE 10(3):e0117700

Tighe PJ, Riley JL 3rd, Fillingim RB (2014) Sex differences in the incidence of severe pain events following surgery: a review of 333,000 pain scores. Pain Med (Malden, Mass.) 15(8):1390-1404

Tsang A, Von Korff M, Lee S et al (2008) Common chronic pain conditions in developed and developing countries: gender and age differences and comorbidity with depression-anxiety disorders. J Pain 9(10):883-891

Wong WS, Fielding R (2011) Prevalence and characteristics of chronic pain in the general population of Hong Kong. J Pain 12(2):236-245

Yeo SN, Tay KH (2009) Pain prevalence in Singapore. Ann Acad Med Singapore 38(11):937-942

Yu HY, Tang Fl, Kuo BI, Yu S (2006) Prevalence, interference, and risk factors for chronic pain among Taiwanese community older people. Pain Manag Nurs 7(1):2-11

Yue P, Liu F, Li L (2012) Neck/shoulder pain and low back pain among school teachers in China, prevalence and risk factors. BMC Public Health 12:789

\section{Submit your manuscript to a SpringerOpen ${ }^{\circ}$ journal and benefit from:}

- Convenient online submission

- Rigorous peer review

- Immediate publication on acceptance

- Open access: articles freely available online

- High visibility within the field

- Retaining the copyright to your article

Submit your next manuscript at $\boldsymbol{\nabla}$ springeropen.com 